\title{
DEVELOPMENT OF INTENSITY DURATION FREQUENCY CURVES FOR NARSAPUR MANDAL, TELANGANA STATE, INDIA
}

\author{
Rambabu Palaka', G. Prajwala ${ }^{2}$, K.V.S.N. Navyasri ${ }^{3}$, I. Sitaram Anish ${ }^{4}$ \\ ${ }^{I}$ Associate Professor, Department of Civil Engineering, B.V. Raju Institute of Technology, Narsapur \\ ${ }^{2,3,4}$ UG Student, B. Tech, Civil Engineering, B.V. Raju Institute of Technology, Narsapur
}

\begin{abstract}
The government of Telengana State, India, has taken up restoration of minor irrigation tanks to store its maximum capacity under a massive programme called "Mission Kakatiya". For estimation of runoff into these tanks, intensity of rainfall for shorter duration is required. Hence, an attempt is made in this study to generate intensity of rainfall for durations from 1-hour to 12-hour using an empirical formula from Indian Meteorological Department (IMD). Frequency analysis using Gumbel's Extreme Value Distribution method is considered to establish Intensity-Duration-Frequency curves. Daily rainfall data for the years $2009-14$ of Narsapur Mandal, Medak District, Telengana State, India, is taken for the analysis considering various return periods of 5 Year, 10 Year, 25 Year, 50 Year and 100 Years.
\end{abstract}

Keywords: Intensity Duration Frequency (IDF) Curves, Gumbel's Extreme Value Distribution, Rainfall Intensity, Short Duration Rainfall, IDF Empirical Equation

\section{INTRODUCTION}

The people of the Telangana State are highly dependent on the minor irrigation tanks which are spread across all the 10 districts due to its geographical location. By knowing the importance of tanks, the Government of Telangana State has initiated a minor irrigation tank restoration program under the title Mission Kakatiya. As per the survey conducted in 2014, the total numbers of minor irrigation tanks are observed around 46,531. This program is designed for next five years by the Irrigation Department, taking up 20\% of the tanks each year.

One of important activity of Tanks Restoration Programme is strengthening of bunds considering peak runoff. For estimation of runoff into these tanks short duration rainfalls are required. However the data available for study area is mostly daily rainfall data. Hence, short duration rainfall data is obtained for short durations from the daily rainfall data using an empirical reduction formula (IMD). To prepare Intensity-Duration-Frequency (IDF) curves, Frequency Analysis is useful considering various Return Periods.

\section{STUDY AREA}

The study area comprises of Narsapur mandal of Medak district, which lies between $17.66^{\circ}$ and 17.840 North Latitudes and 78.170 and 78.320 East Longitudes. Narsapur mandal comprises of 33 revenue villages with a population of 53,774 as per Census 2011. The annual maximum rainfall distribution for rainy season i.e., June to October, of Narsapur mandal for the period from 2009 to 2014 is shown in Table 1 . While the average daily rainfall of the area is $95.50 \mathrm{~mm}$, the actual maximum daily rainfall received ranges from a minimum of $53.80 \mathrm{~mm}$ in 2011 to a maximum of $156.40 \mathrm{~mm}$ in July 2010, in the period of 6 years.

Table 1. Annual Maximum Daily Rainfall

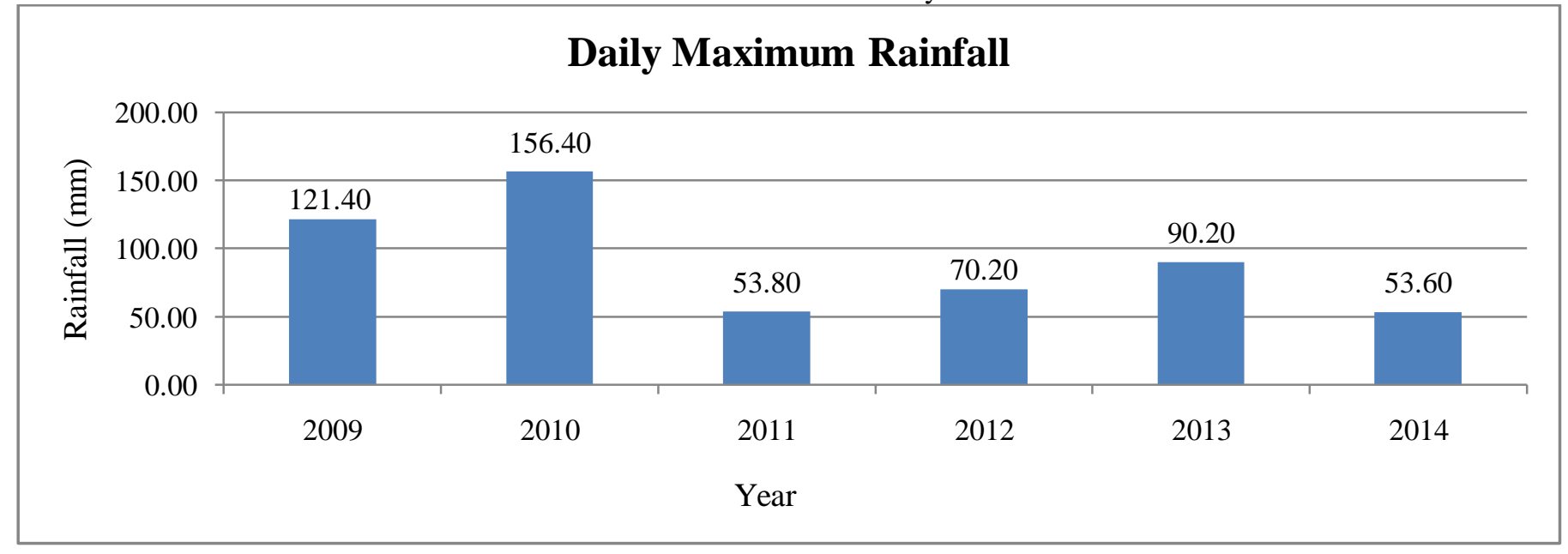




\section{INTENSITY-DURATION-FREQUENCY CURVES}

Intensity-Duration-Frequency curve is useful to predict the average rainfall intensity of a storm event to the duration of storm for a given return period. Normally, Rainfall Intensity in $\mathrm{mm} / \mathrm{hr}$ is plotted on the $\mathrm{y}$-axis and duration in hours is on the x-axis. The construction of IDF curves requires the continuous records of rainfall data.

\section{METHODOLOGY}

The following procedure is followed for preparation of IDF curves.

\section{Step 1: Collection of annual daily rainfall data}

Daily rainfall data from the years 2009 to 2014 is used to obtain recent trends in the rainfall intensity.

Step 2: Preparation of short duration rainfall data Using IMD formula, shorter duration rainfall series is generated from Daily Rainfall data and shown in Table 2.

Where

$$
P_{t}=P_{24}(t / 24)^{1 / 3}
$$

$\mathrm{P}_{\mathrm{t}}=$ Rainfall in $\mathrm{mm}$ for $\mathrm{t}$ hours duration

$\mathrm{P}_{24}=$ Daily Rainfall data in $\mathrm{mm}$

$\mathrm{t}=$ Shorter duration in hours

Table 2. Shorter Duration Rainfalls Derived from Max. Daily Rainfall using IMD 1/3 rd rule

\begin{tabular}{|c|c|c|c|c|c|c|c|c|c|c|c|c|c|}
\hline Month & $\begin{array}{l}\text { 30 } \\
\text { min }\end{array}$ & $1 \mathrm{hr}$ & $2 \mathrm{hr}$ & $3 \mathrm{hr}$ & $4 \mathrm{hr}$ & $5 \mathrm{hr}$ & $6 \mathrm{hr}$ & $7 \mathrm{hr}$ & $8 \mathrm{hr}$ & $9 \mathrm{hr}$ & $10 \mathrm{hr}$ & $11 \mathrm{hr}$ & $12 \mathrm{hr}$ \\
\hline 2009 & 33.40 & 42.09 & 53.03 & 60.70 & 66.81 & 71.97 & 76.48 & 80.51 & 84.17 & 87.54 & 90.67 & 93.60 & 96.36 \\
\hline 2010 & 43.04 & 54.22 & 68.31 & 78.20 & 86.07 & 92.72 & 98.53 & 103.72 & 108.44 & 112.78 & 116.82 & 120.59 & 124.13 \\
\hline 2011 & 14.80 & 18.65 & 23.50 & 26.90 & 29.61 & 31.89 & 33.89 & 35.68 & 37.30 & 38.80 & 40.18 & 41.48 & 42.70 \\
\hline 2012 & 19.32 & 24.34 & 30.66 & 35.10 & 38.63 & 41.62 & 44.22 & 46.55 & 48.67 & 50.62 & 52.43 & 54.12 & 55.72 \\
\hline 2013 & 24.82 & 31.27 & 39.40 & 45.10 & 49.64 & 53.47 & 56.82 & 59.82 & 62.54 & 65.05 & 67.37 & 69.55 & 71.59 \\
\hline 2014 & 14.75 & 18.58 & 23.41 & 26.80 & 29.50 & 31.77 & 33.77 & 35.55 & 37.16 & 38.65 & 40.03 & 41.33 & 42.54 \\
\hline Mean & 25.02 & 31.52 & 39.72 & 45.47 & 50.04 & 53.91 & 57.28 & 60.30 & 63.05 & 65.57 & 67.92 & 70.11 & 72.17 \\
\hline S.D. & 11.29 & 14.22 & 17.92 & 20.51 & 22.58 & 24.32 & 25.85 & 27.21 & 28.45 & 29.59 & 30.65 & 31.63 & 32.57 \\
\hline
\end{tabular}

\section{Step 3: Probability Distribution}

In this study, Gumbel's Extreme Value distribution method is used for probability distribution for each selected duration data series.

Chow (1951) has shown that hydrological studies can be expressed by the following equation of the hydrologic frequency analysis:

The rainfall $\left(\mathrm{P}_{\mathrm{T}}\right)$ corresponding of a given return period $(\mathrm{T})$ using the Gumbel's Distribution is given by:

$\mathrm{P}_{\mathrm{T}}=\boldsymbol{\sigma}+\mathrm{K} . \mathrm{S}$

Where

$\boldsymbol{\sigma}=$ Average Annual Daily Maximum Rainfall

$\mathrm{S}=$ Standard Deviation of Annual Daily Maximum Rainfall

$\mathrm{K}=$ Frequency Factor given by:

$$
\mathrm{K}=\frac{\sqrt{6}}{\pi}\left[0.5772+\ln \left[\ln \left[\frac{\mathrm{T}}{\mathrm{T}-1}\right]\right]\right.
$$

Using above equation, Frequency Factors for the return periods of $5,10,25,50$ and 100 years are calculated and those values are $0.72,1.30,2.04,2.61$, and 3.14 respectively. The above values of frequency factor are used to obtain $\mathrm{P}_{\mathrm{T}}$ corresponding to return periods of $5,10,25,50$ and 100 years for durations of 1 to 12 Hours.

Then, the intensity of rainfall $\left(\mathrm{I}_{\mathrm{T}}\right)$ is obtained for the return period $\mathrm{T}$ from the below equation:

$$
\mathrm{I}_{\mathrm{T}}=\frac{\mathrm{P}_{\mathrm{t}}}{\mathrm{T}_{\mathrm{d}}}
$$

Where $T_{d}$ is duration in hours.

The frequency of the rainfall is usually defined by reference to the annual maximum series, which consists of the largest values observed in each year. 
Table 3. Rainfall Intensity in $\mathrm{mm} / \mathrm{hr}$ at various rainfall durations and return periods for Narsapur Mandal by Gumbel's Extreme Value Distribution

\begin{tabular}{|l|l|l|l|l|l|l|l|}
\hline Duration (Hr) & Mean & S.D. & $\mathbf{5}$ Year & 10 Year & 25 Year & 50 Year & 100 Year \\
\hline $\mathbf{1} / 2$ & 52.56 & 49.05 & 68.31 & 81 & 97.2 & 109.67 & 121.27 \\
\hline $\mathbf{1}$ & 33.11 & 30.9 & 43.03 & 51.03 & 61.23 & 69.09 & 76.4 \\
\hline $\mathbf{2}$ & 20.86 & 19.47 & 27.11 & 32.15 & 38.57 & 43.52 & 48.13 \\
\hline $\mathbf{3}$ & 15.92 & 14.86 & 20.69 & 24.53 & 29.44 & 33.21 & 36.73 \\
\hline $\mathbf{4}$ & 13.14 & 12.26 & 17.08 & 20.25 & 24.3 & 27.42 & 30.32 \\
\hline $\mathbf{5}$ & 11.32 & 10.57 & 14.72 & 17.45 & 20.94 & 23.63 & 26.13 \\
\hline $\mathbf{6}$ & 10.03 & 9.36 & 13.03 & 15.45 & 18.54 & 20.92 & 23.14 \\
\hline $\mathbf{7}$ & 9.05 & 8.44 & 11.76 & 13.95 & 16.73 & 18.88 & 20.88 \\
\hline $\mathbf{8}$ & 8.28 & 7.73 & 10.76 & 12.76 & 15.31 & 17.27 & 19.1 \\
\hline $\mathbf{9}$ & 7.65 & 7.14 & 9.95 & 11.79 & 14.15 & 15.97 & 17.66 \\
\hline $\mathbf{1 0}$ & 7.13 & 6.66 & 9.27 & 10.99 & 13.19 & 14.88 & 16.46 \\
\hline $\mathbf{1 1}$ & 6.69 & 6.25 & 8.7 & 10.32 & 12.38 & 13.97 & 15.45 \\
\hline $\mathbf{1 2}$ & 6.32 & 5.9 & 8.21 & 9.74 & 11.68 & 13.18 & 14.58 \\
\hline
\end{tabular}

Step 4: Preparation of IDF Curves

By using data shown table 3, Intensity Duration Frequency curves are plotted for various return periods as shown in
Figure 1. It is observed that intensity value decreases as duration increases.

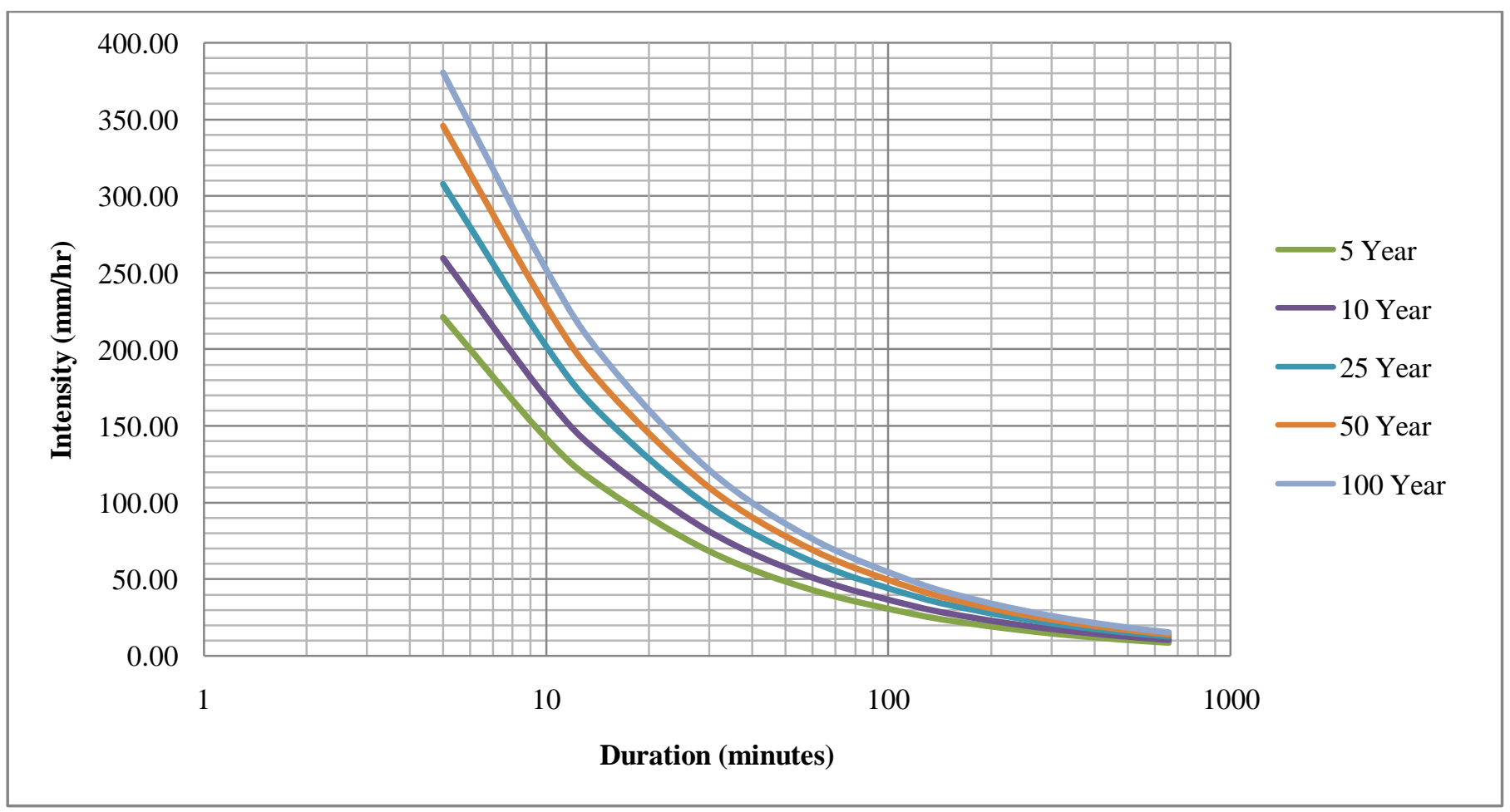

Figure 1. Intensity Duration Frequency curve (semi-log curve) of Narsapur Mandal 
The same Intensity duration frequency curve (log curve) is shown in Figure 2. It is observed that the Intensity Duration Frequency is a straight line and the value of intensity is decreasing intensity with duration.

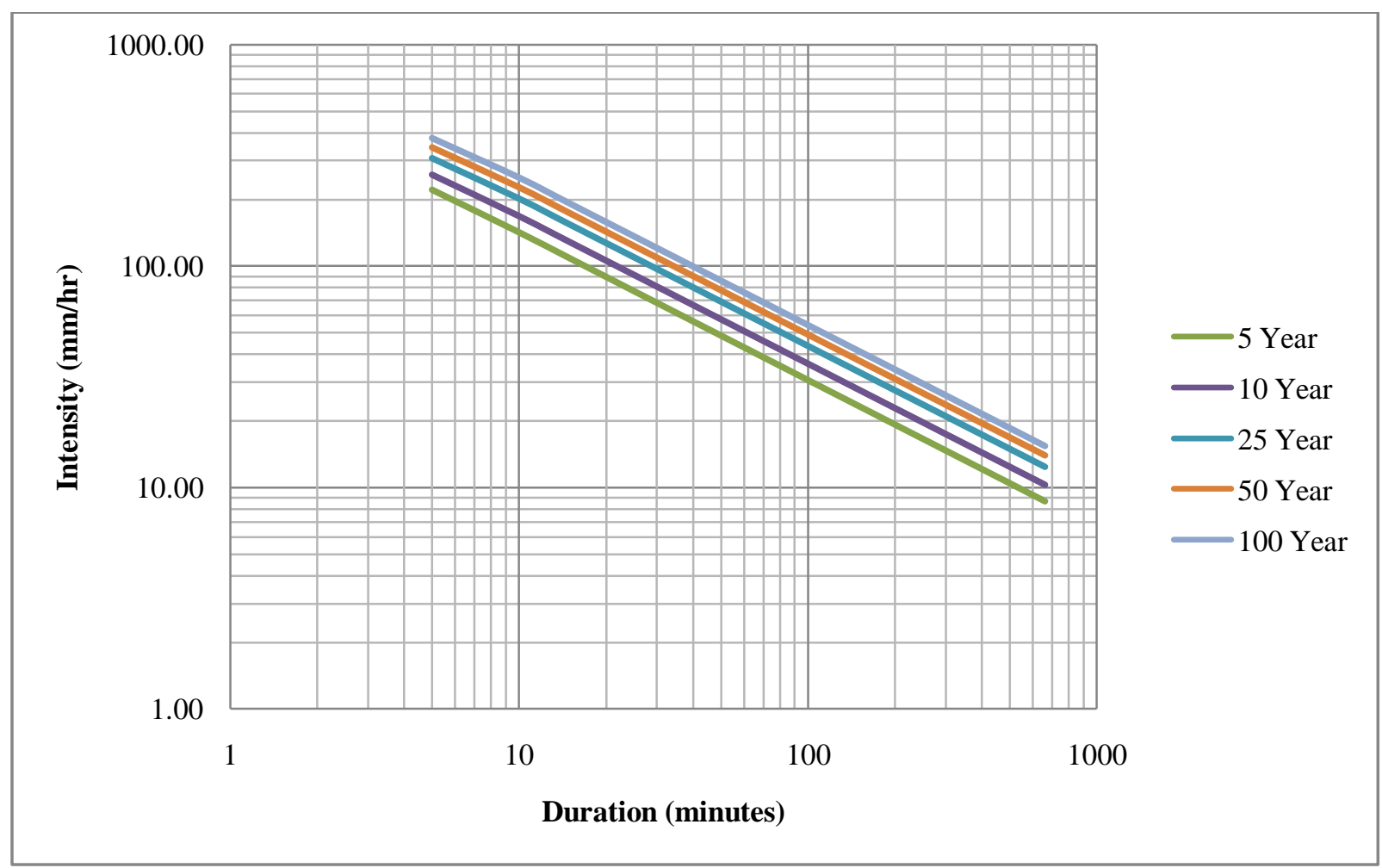

Figure 2. Intensity duration frequency curve in log paper for Narsapur Manadal

To estimate the maximum rainfall intensity for different duration and return periods the following empirical equation is used.

$\mathrm{i}=\mathrm{x} *\left(\mathrm{t}_{\mathrm{d}}\right)^{-\mathrm{y}}$

Where,

$\mathrm{i}=$ rainfall intensity in $\mathrm{mm} / \mathrm{hr}$,

$\mathrm{t}_{\mathrm{d}}=$ rainfall duration in minutes and

$\mathrm{x}$ and $\mathrm{y}$ are the parameters to fit the IDF curve

Least Square method is used to find parameters $\mathrm{x}$ and $\mathrm{y}$ for various return periods and the results are shown in Table 4.

Table 4. Empirical Equations for corresponding return

\begin{tabular}{|l|l|l|l|l|}
\multicolumn{2}{|c}{ period with Correlation Coefficient } \\
\hline $\begin{array}{l}\text { Return } \\
\text { Period } \\
(\text { Years) }\end{array}$ & $\mathbf{x}$ & $\mathbf{y}$ & $\begin{array}{l}\text { Intensity, } \mathbf{i}=\mathbf{x} * \\
\left(\mathbf{t}_{\mathbf{d}}\right)^{-\mathbf{y}}\end{array}$ & $\begin{array}{l}\text { Correlation } \\
\text { coefficient, } \\
\mathbf{R}\end{array}$ \\
\hline 5 & 653 & 0.66 & $\mathrm{i}=653 *\left(\mathrm{t}_{\mathrm{d}}\right)^{-0.66}$ & 1 \\
\hline 10 & 770.2 & 0.66 & $\mathrm{i}=770.2 *\left(\mathrm{t}_{\mathrm{d}}\right)^{-0.66}$ & 1 \\
\hline 25 & 919.8 & 0.66 & $\mathrm{i}=919.8 *\left(\mathrm{t}_{\mathrm{d}}\right)^{-0.66}$ & 0.999 \\
\hline 50 & 1035 & 0.66 & $\mathrm{i}=1035 *\left(\mathrm{t}_{\mathrm{d}}\right)^{-0.66}$ & 0.999 \\
\hline 100 & 1142 & 0.66 & $\mathrm{i}=1142 *\left(\mathrm{t}_{\mathrm{d}}\right)^{-0.66}$ & 0.999 \\
\hline
\end{tabular}

\section{CONCLUSION}

In this study, Gumbel's Extreme Value Distribution method is considered as the best approximation of rainfall intensity for return periods of 5, 10, 25, 50 and 100 years. The results shows a good match as the correlation coefficient is observed greater than 0.999 . This indicated that the empirical formula obtained to estimate intensity in the study area is good for short durations. These IDF Curves and Empirical Equations will help for calculation of peak discharge into Minor Irrigation Tanks and also useful for planning and designing of any water resource management project.

\section{REFERENCES}

[1]. M. M. Rashid Et Al, Modelling Of Short Duration Rainfall Intensity Duration Frequency (Sdr-Idf) Equation For Sylhet City In Bangladesh. Arpn Journal Of Science And Technology, Issn 2225-7217, Vol.2, No.2, March 2012.

[2]. Chowdhury Et Al, Short Duration Rainfall Estimation Of Sylhet: Imd And Uswb Method. Journal Of Indian Water Works Association. Pp. 285-292, 2007

[3]. Lamia Abdul Jaleel Et Al, Developing Rainfall Intensity-Duration-Freqency Relationship For Basrah City, Kufa Journal Of Engineering (K.J.E) Issn 22075528 Vol. 5, Issue 1, Dec., 2013,P.P.105-112.

[4]. Munshi Md. Rasel Et Al, Modeling Rainfall Intensity Duration Frequency (R-Idf) Relationship For Seven Divisions Of Bangladesh, European Academic Research Vol. Iii, Issue 5/ August 2015.

[5]. Jahnvi P. Bhatt Et Al, Generation Of Intensity Duration Frequency Curve Using Daily Rainfall Data For Different Return Period, Journal Of International Academic Research For Multidisciplinary Impact Factor 1.393, Issn: 2320-5083, Volume 2, Issue 2, March 2014. 
[6]. Zameer Ahmed Et Al, Rainfall Intensity Variation For Observed Data And Derived Data - A Case Study Of Imphal, Arpn Journal Of Engineering And Applied Sciences, Vol. 7, No. 11, November 2012

[7]. Daniel Dourte Et Al, Rainfall Intensity-DurationFrequency Relationships For Andhra Pradesh, India: Changing Rainfall Patterns And Implications For Runoff And Groundwater Recharge, Journal Of Hydrologic Engineering · March 2013.

[8]. Chow V.T. 1964. Handbook Of Applied Hydrology, Mcgraw- Hill, New York. 9-49, 9-62.

[9]. Elsebaie, H., Ibrahim," Developing Rainfall IntensityDuration-Frequency Relationship For Two Regions In Saudi Arabia", Journal Of King Saud University, Engineering Resource, 2010.

[10].F. Y. Logah, K Et Al, Developing Short Duration Rainfall Intensity Frequency Curve For Accra In Ghana. International Journal Of Latest Research In Engineering And Computing. Volume 1, Issue 1 : Page No. 67-73, September- October 2013 